conclude that the blood ressels are the highway of com. munication. But clinical investigation gives us little evidence that the stream is toxaemic. We are, too, continually con ronted by the difficulty of deciding whether post hoc is in conflict with propter, or on the same side. The characteristics of the iritis are not pathognomonic. Deposits on the posterior surface of the cornea may or may not be present. The iritis is an anatomical lesion capable of initiation by manifold organisms, but it is an iritis and nothing more. Lacking the nodules of tubercle, and the condylomata of syphilis, it begins insidiously, progresses leisurely, and clears up tardily. If the iris alone be treated relapses will occur, but if the canse be discorered and removed a satisfactory prognosis may confidently be given.

It is, I think, agreed that prorrhoea alreolaris is the most frequent source of toxaemic iritis, and the reasons would seem to be, first, the great prevalence of pyorrhoea, and, secondly, that the infection in these cases is direct into the circulation, whereas in many other forms of alimentary toxaemia the toxins hare to undergo the ordeal of the hepatic furnace. But this preralence of pyorrhoea may lead us astray if, on finding it present, we at once conclude it to be the canse. It cannot be too insistently brought to mind that a patient with pyorrhoea may also be a sufferer from syphilis or gonorrhoea. There may also be present more than one source of "gastro-intestinal autointoxication," evidences of which may be unexpectedly manifested when the urine and faeces are examined. Whatever organ is discovered at fault it should receive treatment at once, the patient being referred to the proper authority-physician, surgeon laryngologist, rhinologist, aurist, or dentist-without delay. In the case of pyorrhoea the latter will naturally wish to sare as many teeth as possible, but when iritis is already established the bias should be in farour of drastic treatment of the periodontal foci of disease. The slower methods by autogenous raccines, and by local applications to the alreolar pockets, may suffice before the onset of iritis, but the important point is to stop the auto-intoxication by the most expeditions method; that is, to remove all the affected teeth. The cure of the iritis is of paramount importance, and it is better to lose thirty-two teeth than one eye. Whether the oral sepsis is the cause or the result of intestinal stasis should malie no difference in the verdict; the teeth must suffer the penalty for guilt as accessories before or after the event. When dental treat. ment has been carried out, although immediate cure may not follow, we have at least remored a fruitful source of general ill-health, thereby increasing the power of re sistance and simplifying the rork which atropine will consummate. In the treatment of iritis the primary cause calls with insistent voice for detailed hygiene. Salicylic acid may have a specific action in acute rheumatisn, but in iritis, apart from its anodyne effects, it is probably quite useless. The old formula of mercury and chalk is beneficial, but raccines have proved disappointing. Occasionally a case seems to respond most satisfactorily, but in many no adrantage accrues.

I will not take up time by considering the question of diet, except to remark that we shall see less pyorrhoea, and therefore less iritis, when finely ground flour as an article of food is banished from our homes. Some day perchance it will be illegal to balie or to buy, to sell or to swallow, bread made from flour which bakers call "firsts."

The autointoxication theory of the origin of fibrositis, rheumatoid arthritis, and other diseases inrolves such a revcrsal of old teaching, such a change in diagnosis and treatment, that it is not easy to riew the subject in all its bearings. As far as the eye is concerned, the iconoclastic conclusion to which we are led is that iritis is an indication of an infective process in some part of the body, and, conversely, that infection or subinfection is an indication that iritis may be threatening. I have called the subject of this address toxaemic iritis in order to intimate the point to which I wished to draw attention, but the infectire theory connotes a toxaemic basis for all types of iritis. No iritis is primary ; it is invariably secondary, almays infective.

In the future statistics should show a decreased inciacnce of diseases of the eye if it be proved that those ihcumatic tringes which hare hitherto been accounted for by morning mist or evening chill are early warnings of a chronic septic invasion.

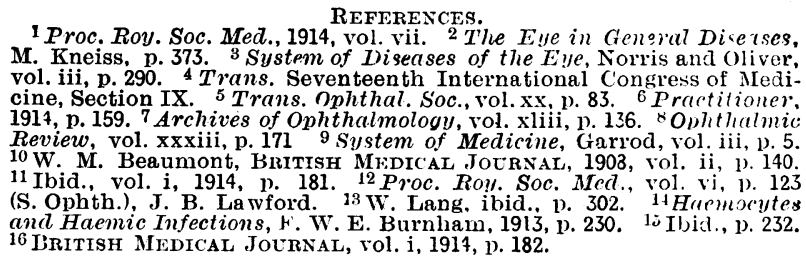

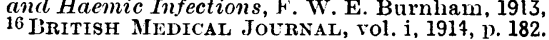

INSECTS AND WAR:

II.-THE BED-BUG (Cimex lectularius).

BY

A. E. SHIPLEY, Sc.D., F.R.S.,

MASTEI OF CHRIST'S COLLEGE, CAMBBRIDGi.

In " $\mathrm{x}$ " finita tria sunt animalia dira;

Sunt pulices fortes, cimices, culicumque cohortes;

Sed pulices saltu fugeunt, culicesque volatu

Et cirnices pravi nequeunt foetore necari.

Awong the numerous disagreeable features of the bed-bug is the fact that it has at least two scientific names-Cimex (under which name it was known to the classical writersi and Acanthia. The latter name is favoured by French and some German authorities, but Cimex was the name adopted by Linnaeus and is mostly used by British writers, and will be used throughout this article. One cannot do better than take the advice of that wise old entomologist, Dr. David Sharp, and allow the name "Acanthia to fall into disuse."

The species which is the best linown in England is C. lectularius, but there is a second species which is much commoner in warm climates (C.rotundatus). As regards carrying disease, this latter species is even more dangerous than its more temperate relative. Other species, which rarely if ever attack man, are found in pigeon-houses and dove-cotes, martins' nests, poultry. houses, and the homes of bats.

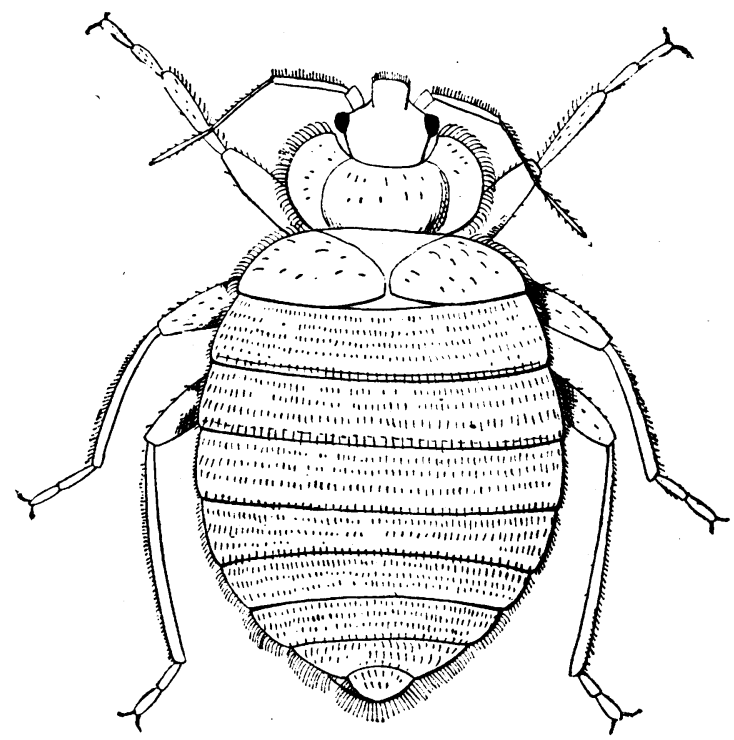

Fig. 1.-Cimex lectularius, male. $\times 15$. (From Brumpt.)

The common bed-bug seems to have arrived in England about the same time as the cocliroach-that is, some four hundred years ago. Apparently it came from the East, and was at first confined to seaports and harbours. It seems to have been first montioned by play-writers early in the seventeenth century. How the insect got the name of "bug" is unknown. It has been suggested that the old English word "bug," meaning a ghost or phantom which walked by night, has been transferred to Cimex. This may be so, but the Oxford Dictionary tells us that proof is lacking.

The insect is some $5 \mathrm{~mm}$. in length and about $3 \mathrm{~mm}$. in breadth, and is of a reddish or brownish rusty colonr, 
fading into black. Its body is extraordinarily flattened so that it can readily pass into chinks or between splits in furniture and boarding, and this it does whenever claylight appears, for the bug lores darkness rather than light. The head is large, and ends in a long piercing, four-jointed proboscis, which forms a tube with four piercing stylets in it. As a rule the proboscis is folded back into a groore, which reaches to the first pair of legs on the under' surface of the thorax. The head bears two black eyes and two four-jointed antennae. Each of the six legs is provided with two claws, and all the body is covered with fairly numerous hairs. The abdomen shows seven visible segments and a terminal piece. The bug has no fixed period of the year for breeding, but as long as the temperature is favourable and the food abundant generations will succeed each other without pause, but should the weather turn too cold the insects become numbed and their vitality and power of reproduction are interrupted until warmth returns.

Like the cockroach, the bed-bug is a frequenter of human habitations, but only of such as have reached a certain stage of comfort. It is said to be very rare in the homes of savages, but it is only too common in the poorer quarters of great cities. Its presence does not necessarily indicate neglect or want of cleanliness. It is very apt to get into trunks and luggage generally, and in this way is conveyed even into the best kept homes; it is also very migratory and will pass readily from one house to another, and when an infested dwelling is vacated the insects usually leave it for better company and quarters. Their food supply being withdrawn they make their way along gutters, water-pipes, etc., into adjoining and inhabited houses. Cimex is particularly common in ships, especially emigrant ships, and, although unknown to the Indians of North America, it appear's to have entered that continent with the Mayflower.

One of the most disagreeable features of the bed-bug is that it produces an oily fluid which has a quite intolerable odour; the glands secreting this fluid are situated in various parts of the body. The presence of such glands in free-living, hemipterous insects undoubtedly is a pro. tection-birds will not touch them. One, however, fails to see the use of this property in the bed-bug. At any rate it does not deter cockroaches and ants, as well as other- insects, from devouring the Cimex. There is a small black ant which is said to clear a house of these pests in a few days, but one cannot always command its services. Another remarkable feature is that the insect has no wings, although in all probability its ancestors possessed these useful appendages. As the American poet says :

The Lightning-bug has wings of gold,

The June-bug wings of flame.

The bed-bug has no wings at all

But it gets there all the same.

The power of "getting there" is truly remarkable. Man, their chief victim, has always warred against bugs, yet, like the poor, bugs are always with us. I have heard it stated, when I was living in Southern Italy, that if you submerged the legs of your bed in metal saucers full of water and placed the bed in the centre of the room, the bugs will crawl up the wall, walk along the ceiling and drop on to the bed and on to you. Anyhow, whether this be so or not, there is no doubt that these insects have a certain success in the struggle for life, and only the most systematic and rigorous measures are capable of ridding a dwelling of their presence.

The eggs of the bed-bug are pearly white, oval objects, perhaps $1 \mathrm{~mm}$. in length. At one end there is a small cap surrounded by a projecting rim, and it is by pushing off this cap through the orifice thus opened that the young bug makes its way into the outer world after an incubation period of a week or ten days. There is no metamorphosis, no caterpillar and no chrysalis stages. The young hatch out, in structure miniatures of their parents, but in colour they are yellowish-white Fig. 2.- Egg of and nearly transparent. The young Cimex lectularius. forms feed readily, and feeding takes place between each moult, which are five in number, before the adult imago emerges.' This it does about the eleventh or twelfth week after hatching. These time limits depend, howerer, upon the temperature after hatching, and the rate of growth depends not only upon the temperature but on the amount of food. When bred artificially and under good conditions, the rate of progress can be "speeded up" so that the eggs hatch out in eight days, and every following moult takes place at intervals of eight days, so that the period from egg to adult can bo run through in as short a time as seven weelis. Unless fed after each moult, the following moult is indefinitely postponed. Hence it follows that in the preliminary stages they must bite their host five times before tho adult form emerges, and this in turn must have a meal before it lays its eggs. These are deposited in batches of from five to fifty in cracks and crevices, into which the insects have retired for concealment.

Bugs can, however, live a very long time without a meal. Cases are recorded in which they have been kept alive for more than a year incarcerated in a pill-box. When the pill-box was opened, the bugs appeared to bc as thin as paper and almost transparent, but they had managed to produce some offspring. De Geer kept several in a sealed bottle for more than a year, and this power of existing without food may explain the fact that vacated houses occasionally swarm with bugs even when there have been no human beings in the neighbourhood for many months.

'T'he effect of their bite varies in different people. As a rule, the actual bite lasts for two or three minutes beforc the insect is gorged, and at first it is painless. But ver. soon the bitten area begins to swell and to become red,
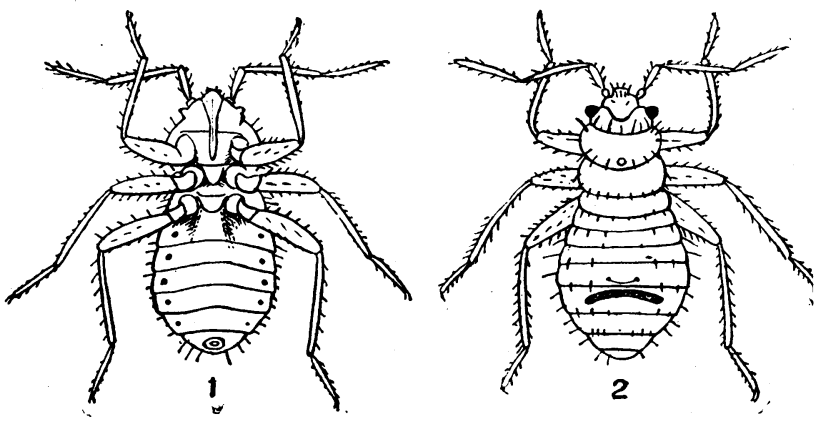

Fig. 3.-Newly hatched young of Cimex lectu?arius. 1, Ventral view: 2 , dorsal view. Enlarged.

and at times a regular eruption ensues. The irritation may be allayed by washing with menthol or ammonia. Some people seem immune to the irritation, and I know friends who in the West Indian islands have slept through the attacks of thousands of bugs, and only awoke to their presence when in the morning they found their night clothing and sheets red with their blood, which, in rolling over in their sleep, they had expressed from the bodies of their tormentors.

As a rule, the uncovered parts of the body-the face, the neck, and the hands-are more bitten than the parts which lie under the bedclothes.

The bug has been accused of conveying many diseasestyphus, tuberculosis, plague, and a form of recurrent ferer produced by a spirochaete (Spirochaeta obermeieri), but a critical examination throws some doubt upon the justice of the accusation, and Professor C. J. Martin writes as follows:

There is really no evidence to incriminate the bed. bug in the case of either typhus or relapsing fever. It is possible to transmit plague experimentally by means of bugs, but there is no epidemiological reason for supposing this takes place to any extent in nature.

There are two differences in the habits of bugs and those of fleas and lice which may possess epidemiological significance. The first concerhs the customary intervals between their meals. Bugs show no disposition to feed for a day or two after a full meal, whereas fleas and lice will suck blood several times during the twenty-four hours. The second is in respect to the time the insects retain a meal and the extent to which it is digested before being excreted., Eleas and lice if constantly fed freely empty their alimentary canals, and the nature of their faeces indicates that the blood has undergone but little digestion. 
Both these insects evacuate such undigested or halfdigested blood per rectum during the act of feeding, and the remnants of the previous meal are thus deposited in the immediate vicinity of a fresh puncture. It is not unlikely that, should the alimentary canal of the insect be infected with plague bacilli, spirochaete, or the organism responsible for typhus fever, these may be inoculated by rubbing or scratching. Buss have not this habit, and in all the cases I have cxamined their clejections were fully digested, almost free from protein, and consisted mostly of alkaline haematin.

Whether bugs be guilty of these crimes or not, they are the cause of an intense inconvenience and disoust, and should, if possible, be dealt with drastically. At the present time there are rumours that one of our largest camps is infested with these insects, and there seems no doubt that some of the prisoners and refugecs to this country have brought their fauna with them, and this fauna is very capable of spreading in concentration canips. The erection of wooden huts, no doubt a pressing necessity, will afford convenient quarters for these pests.

Among the measures which have been most successful in the past has been fumigating houses with hydrocyanic acid gas, but this is a process involving considerable danger and should only be carried out by competent people under the most rigorous conditions. In all fumigating experi. ments every crack and cranny of a house should be shut, windows closed, keyholes blocked, and so on $A$ second method of fumigation is that of burning sulphur. Four ounces of brimstone are placed in a saucer, which in its turn is placed in a larger vessel. This protects the floor of the room from a possible overflow of the burning material. After all apertures have been successfully plugged, four or five hours of the sulphurous fumes are said to be sufficient to kill the bugs, but to ensure success a longer time is needed. This is not only a much less expensive but a much less dangerous operation than using hydrocyanic acid gas Two pounds of sulphur will suffice for each thousand cubic feet of space, but it is well to leave the building closed for some twenty-four hours after the fumigation. Another more localized method of destroying these pests is the liberal application of benzine, kerosene, or any other petroleum oil. These must be introduced into all crevices or cracks with small brushes or feathers, or injected witl syringes. In the same way oil of turpentine or corrosive sublimate has proved effective. Boiling water is also effective when it can be used, and recently in the poorer quarters of London the "flares" which painters use in burning off paint have proved of great use in ridding matchboarding, or wainscoting, or wood for hoarding of bugs. Passed quickly along, the flame does not brum the wood, but it produces a temperature which is fatal to the bug and to its young, and to its eggs.

\section{THE TREATMENT OF ACUTE GONORRHOEA IN THE MALE.}

\section{By W. WYNDHAM POWELL, F.R.C.S.Eng.,} SURGEON TO THE WESTMINSTER GENERAL DISPENSARY.

As one who studied this subject under Janet in Paris, and under the late Dr. Valentine of New York, nearly twenty ycars ago, and has been since constantly engaged in the irrigation treatment, may $I$ be allowed to offer a few remarks?

The nature of this disease, and the secrecy with which its treatment is surrounded in this country, accounts in a great measure for the haphazard way in which it is treated, and for the unsatisfactory nature of the teaching on the subject. The article by Dr. Hayes in the BrItish Medical J JuRnal of September 12th, p. 469, and the remarks thereon by Dr. J. C. McWalter in the ensuing number (p. 523), show that opinions are stilı divided as to whether the active or the expectant treatment is the better in acute gonorrhoea.

The reason is not far to seek. The irrigation treatment, juclging by what one sees and hears, is not easy to learn. Faulty technique is probably at the bottom of most failures. The two-way tube or nozzle which is often used is inferior to the one-hole nozzle as recommended by Janet and Valentine. It is essential to flush out the anterior urethra with considerable force if the treatment is to be effective. A hydrostatic pressure of at least $6 \mathrm{ft}$ is necessary. The urethra must be ballooned ont, and what is also important, rapidly empticd, so that the fluic spurts out with great force. These essentials are obtained by using a nozzle with a bore equal to 8 or 9 of tho French scale, and its partial removal from the meatus or the relaxation of the finger and thumb pressure blocking the meatus around the nozzle ensures a rapid emptying of the canal in the moment following its over-distension.

The process, then, consists of a quick filling and partial emptying of the urethra. This ensures a free circulation of powerful currents right up to the compressor urethrae muscle. The over-distension of the elastic urethra and its recoil facilitate the entry of the fluid into the lacunae and ducts of Littre. With the two-way nozzle the dis. tension of the urethra is a sustained one, with probably no circulation of the fluid in the neighbourhood of the bulb of the urethra. Only in hyperacnte cases is it necessary to go a little more gently, and also rarely when the spongy body itself has been allowed to become infiltrated. In these cases, even with a 2 per cent. solution of cocaine, the proceeding may be painful.

In the early stage, where only the first 2 or 3 inches of the urethra are involved, the whole anterior urethra should be irrigated with the usual full pressure. A splice of healthy mucous membrane treated with potassium permanganate irrigations offer's an almost insuperable barrier to the inward spread of gonorrhoea. This salt is almost a specific in these circumstances. Irritating solutions such as those of silver nitrate, by lowering the vitality of the healthy membrane, favour rather than retard the spread of the disease in acute cases. The same may be said of all irritating hand injections. Permanganate may be used by means of a hand syringe, but the effect is infinitely inferior to that of irrigation.

$A$ few of the chief points to be kept in mind may bo briefly stated:

A strength of from 1 in 5,000 to 1 in 2,000, or eren stronger, is used. The temperature of the solution used is $98^{\circ} \mathrm{F}$. to $100^{\circ} \mathrm{F}$., and the quantity 5 or 6 pints.

For the first three or four days the irrigation is repeated morning and evening with a solution of medium strength, say 1 in 3,000. Then once daily the irrigation is given with a solution of 1 in 2,000. A solution of 1 in 5,000 strength is to be used in very acute and painful cases; 20 drops of a 2 per cent. solution of cocaine may be injected into the urethra and held in for two or three minutes just before irrigating in all sensitive cases. It is astonishing how quickly a painful condition will become painless under this treatiment.

Rapid disappearance of the discharge and recovery is the rule. Should, however, a bead of yellow pus persist, endoscopy will show the lacunac of Morgagni to be greatly swollen and their outlet obstructed. This is evidence that treatment was not begun early enough and that the fluid now cannot penetrate them. In other cases which persist, but with less discharge, the superficial glanifs of Littre will be found more or less extensively involved. This also is found in cases which have been neglected at the beginning. When these conditions exist, in order to hasten recovery and to prevent the organization of infil. trations, the gentle use of Kollman's dilator is indicated, and I can recommend the irrigating dilator. This instrument may be used once or twice a week and very delicately screwed up until just the faintest pressure is felt. It is a powerful machine and requires care in use. The solution mostly used is mercury oxycyanide 1 in 4,000 or stronger. The intraurethral treatment of these affections requires the surgeon to be an expert urethroscopist. An account of the writer's method may be found in the BRITIsH Medical Journal, September 26th, 1908, p. 878.

I have purposely not touched on the subject of the drug treatment of gonorrhoea, as being beyond the scope of this article, and the subject of vesical irrigations for posterior or membrano-prostatic urethritis may be left for a future occasion.

* An account of the irrigation treatment of early gonorrhoes may be found in the Clinical Journal, June 24th, 1908, p. 170, where also my rrigator is fully illustrated.

THE mixed council of the Armenian patriarchate has decicled that couples wishing to get married must first present a medical certificato of health to the proper authority. 